\title{
Notes on Translations, Transliterations and Footnotes
}

My translation of Persian poems is meant to reveal the meaning without any pretence of presenting these translations in a literary form. Persian poets apply many rhetorical embellishments, adorning their speech with metaphors, similes, anagrams, anaphora and a host of other rhetorical figures. I have tried to remain as close to the original text as possible, keeping these figures, especially the metaphors, intact. My analyses are based on the Persian texts.

Except for quoted titles and citations, which keep their own original orthography, Angelicised words and names such as Khan, Shah, and Khomeini keep their English forms. I refer to the 1979 Revolution and the Constitutional Revolution (1906-1911) using capital letters while all other revolutions are written in lower case. Many words are transliterated in their Persian pronunciation and not the Arabic, such as Siyyid and not Sayyid. It is always a challenge to use a transliteration system close to the original language, expressing the pronunciation exactly. My system is mainly based on reading the Persian words correctly and not for a proper pronounciation. For the transliteration of the Persian words I have employed the IJMES transliteration system. The Common Era dates are used throughout the book.

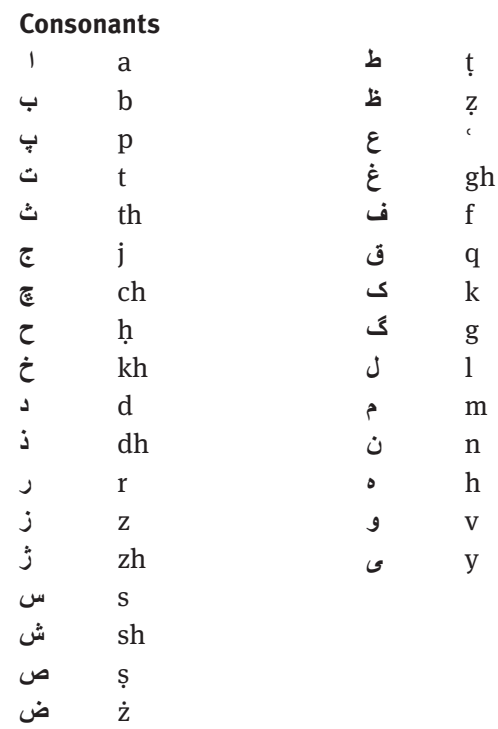

\begin{tabular}{|c|c|c|}
\hline \\
\hline \multirow[t]{2}{*}{ Short } & 6 & $\mathrm{a}$ \\
\hline & 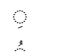 & $\mathrm{i}$ \\
\hline \multirow{3}{*}{ Long } & $1 / 1$ & u \\
\hline & g & $\overline{1}$ \\
\hline & ى & $\overline{1}$ \\
\hline Diphtongs & ى & ey \\
\hline
\end{tabular}


